\title{
Clinicopathological roles of adiponectin and leptin receptors in endometrial carcinoma
}

\author{
HIROMITSU YABUSHITA, KEITA IWASAKI, YUKIHIKO OBAYASHI and AKIHIKO WAKATSUKI
}

Department of Obstetrics and Gynecology, Aichi Medical University, School of Medicine, Nagakute, Aichi 480-1195, Japan

Received June 28, 2013; Accepted January 9, 2014

DOI: $10.3892 / \mathrm{ol} .2014 .1846$

\begin{abstract}
To clarify the roles of adiponectin receptor (AdipoR) and leptin receptor (ObR) in endometrial carcinoma, the expression of AdipoR-1 and -2 and ObR in endometrial cancer was examined immunohistochemically, and correlations with clinicopathological implications were also analysed. Paraffin-embedded tissues were obtained from 77 patients with endometrial carcinoma and were stained immunohistochemically using antibodies against AdipoR-1, AdipoR-2 and ObR. AdipoR-1, AdipoR-2 and ObR were localised predominantly in the cell membrane and cytoplasm of tumour cells and normal endometrial cells. In 77 cases of endometrial cancer, positive expression was observed in 46 cases (59.7\%) for AdipoR-1, 47 cases $(61.0 \%)$ for AdipoR-2 and 33 cases (42.9\%) for ObR. Expression of AdipoR-1 was observed most in stage I cases, G1 tumours, tumours with shallow myometrial invasion, tumours negative for lymphovascular space involvement, cases negative for adnexal invasion and cases with no lymph node metastasis. However, the expression of AdipoR-2 and ObR showed no correlation with any clinicopathological factors. Kaplan-Meier analyses revealed that progression-free and overall survival times were longer in cases with positive AdipoR-1 expression compared with negative AdipoR-1 expression. Poor expression of AdipoR-1, thus, appears to be associated with tumour grade, myometrial invasion, adnexal invasion, lymph-vascular space involvement and lymph node metastasis, as well as poor prognosis, in endometrial cancer.
\end{abstract}

\section{Introduction}

Endometrial cancer is showing rapid increases in mortality and incidence in Japan (1). Previous clinicopathological studies have shown that poor prognosis of endometrial cancer is associated with the histological grade of the tumour,

Correspondence to: Professor Hiromitsu Yabushita, Department of Obstetrics and Gynecology, School of Medicine, Aichi Medical University, 1-1 Yazakokarimata, Nagakute, Aichi 480-1195, Japan E-mail: yab@aichi-med-u.ac.jp

Key words: endometrial carcinoma, adiponectin receptor, leptin receptor, immunohistochemistry presence of malignant cells in ascites or the washing of specimens for cytology, cervical invasion of malignant cells, deep myometrial invasion of malignant cells, lymph node metastasis and involvement of malignant cells in the lymphovascular space (2-4).

Obesity is a well-established risk factor associated with several types of cancer, including endometrial cancer (5-8). The factor linking obesity to endometrial cancer appears to be excessive exposure to various factors produced by adipose tissue. Adipose tissue is a source of oestrogen, insulin and insulin-like growth factors, all of which are considered to be involved in endometrial tumourigenesis $(9,10)$. In addition to these factors, adipose tissues produce various bioactive hormones called adipokines, the most prominent of which are leptin and adiponectin. These may significantly influence the growth and proliferation of tumours (11-13).

Leptin, a product of the obese $(\mathrm{Ob})$ gene, is produced predominantly in adipose tissue and expressed in normal tissues and malignant breast tissues (14-16). Expression of leptin and leptin receptor $(\mathrm{ObR})$ is more frequent in carcinoma than in normal tissue $(17,18)$. Leptin is involved in a variety of functions, including appetite regulation, bone formation, reproduction and angiogenesis (19), and may affect processes associated with cancer initiation and progression, resulting in the development of metastases $(15,17,20,21)$. Leptin acts through $\mathrm{ObR}$, which is encoded by the $\mathrm{Ob}$ gene. Binding of leptin to ObR activates the Janus kinase (JAK)/signal transducer and activator of transcription signalling pathway and induction of JAK stimulates phosphoinositol-3-kinase (PI3-kinase). Activation of PI3-kinase increases cell migration and invasion via the Rac/Rho pathways and stimulates the major growth and survival Akt pathway (13).

Adiponectin is an additional type of adipocytokine, predominantly secreted by adipocytes (12). In contrast to other adipocytokines, adiponectin levels correlate inversely with central fat accumulation (22). Adiponectin may exert antineoplastic activity through suppression of tumour proliferation and neoangiogenesis, and through induction of apoptosis (23-25). In addition, an inverse correlation has been found between plasma adiponectin levels and the histological grade of endometrial cancer (26). However, the precise effects of adiponectin in endometrial cancer remain unclear. In total, two adiponectin receptors (AdipoR-1 and AdipoR-2) have been identified and in vitro studies have shown that the two AdipoR genes are expressed in human monocytes, macrophages, 
adipocytes, vascular smooth muscles, a primary osteoblast cell line, pancreatic cells and other cell types (27-30). Previous in vivo studies have shown that AdipoR-1 is abundantly expressed in skeletal muscle and the liver, whereas AdipoR-2 is predominantly expressed in the liver. Additionally, AdipoR-1 in the liver activates AMP-activated protein kinase pathways, while AdipoR-2 activates peroxisome proliferator-activated receptor pathways $(27,31,32)$. In addition, expression of AdipoR has previously been documented in several human cancer cell lines $(33,34)$.

The aim of the present study was to determine whether the immunohistochemical expression of AdipoR-1, AdipoR-2 or ObR correlates with the clinicopathological manifestations and clinical outcomes of endometrial carcinoma patients.

\section{Materials and methods}

Clinical samples. Formalin-fixed, paraffin-embedded tumour tissues were obtained from 77 patients with endometrioid adenocarcinoma of the endometrium. All patients attended the Gynaecology Clinic at the Aichi Medical University Hospital (Nagakute, Japan) and were diagnosed with endometrial endometrioid adenocarcinoma based on post-surgical assessment. Clinicopathological characteristics of the patients are shown in Table I. Normal endometrial tissue was also obtained from 19 patients with benign uterine disease (uterine leiomyoma, $\mathrm{n}=12$; and uterine prolapse, $\mathrm{n}=7$ ). All study protocols were approved by the regional ethics committee of the Aichi Medical University, School of Medicine (Nagakute, Japan). Written informed consent was obtained from all participants prior to study enrolment.

Immunohistochemistry. The prepared 3- $\mu \mathrm{m}$ sections were deparaffinised and rehydrated. Following microwave processing for $25 \mathrm{~min}$ in $10 \mathrm{mM}$ citrate buffer ( $\mathrm{pH} \mathrm{6.0)}$, sections were incubated for $30 \mathrm{~min}$ in methanol containing $0.5 \% \mathrm{H}_{2} \mathrm{O}_{2}$. Following incubation in normal goat serum for $1 \mathrm{~h}$ at room temperature to block non-specific staining, slides were incubated overnight with the primary antibodies at $4^{\circ} \mathrm{C}$. The primary antibodies used were rabbit anti-human AdipoR-1 (raised against amino acid residues 357-375) antiserum, rabbit anti-human AdipoR-2 (raised against amino acid residues 374-386) antiserum (both purchased from Phoenix Pharmaceuticals, Burlingame, CA, USA) and rabbit anti-human ObR (raised against amino acid residues 541-840) antiserum (Santa Cruz Biotechnology, Inc., Santa Cruz, CA, USA), used at dilutions of 1:500, 1:200 and 1:200, respectively. Anti-rabbit antibody-labelled polymer horseradish peroxidase (ChemMate Envision kit; Dako Japan, Kyoto, Japan) was used as the secondary antibody, applied for $30 \mathrm{~min}$ at room temperature. The horseradish peroxidase reaction was developed with 3,3'-diaminobenzidine tetrahydrochloride (Katayama Chemical Industries Co. Ltd., Osaka, Japan)and sections were counterstained with haematoxylin (Katayama Chemical Industries Co. Ltd.) for microscopic examination (Olympus BX50, Olympus Corp., Tokyo, Japan). Sections were defined as showing positive expression when $>50 \%$ of tumour cells were intensely stained.

Statistical analysis. The statistical significance of differences among different categories of expression was analysed using the $\chi^{2}$ test and two-way analysis of variance. Progression-free and overall survival were analysed using the Kaplan-Meier method and log-rank test, and the potential significance of multiple prognostic factors for progression-free and overall survival were analysed by the Cox proportional hazard regression test. $\mathrm{P}<0.05$ was considered to indicate a statistically significant difference.

\section{Results}

AdipoR-1, AdipoR-2 and ObR localisation. AdipoR-1, AdipoR-2 and ObR were localised predominantly to the cell membrane and cytoplasm of tumour cells (Fig. 1). In normal endometrial tissue, the expression of AdipoR-1, AdipoR-2 and ObR was identified in endometrial glandular cells, in the proliferative and secretory phases. Expression of AdipoR-1 was found in nine of the 10 proliferative-phase specimens and in all nine secretory-phase specimens. In addition, the expression of AdipoR-2 and ObR were found in all 10 proliferative-phase and nine secretory-phase specimens.

AdipoR-1, AdipoR-2 and ObR expression. In the 77 endometrial cancer cases, positive expression was observed in 46 cases (59.7\%) for AdipoR-1, 47 cases (61.0\%) for AdipoR-2 and 33 cases (42.9\%) for ObR. Expression of AdipoR-1 was observed most in stage I cases versus stage II or III cases, G1 tumours versus G2 or G3 tumours, tumours with shallow myometrial invasion versus tumours with deep myometrial invasion, tumours with negative lymphovascular space involvement versus tumours with positive lymphovascular space involvement, cases with negative adnexal invasion versus cases with positive adnexal invasion and cases with negative lymph node metastasis versus cases with positive lymph node metastasis. Conversely, cervical stromal invasion, peritoneal cytology and body mass index exhibited no correlation with AdipoR-1 expression (Table II). However, expression of AdipoR-2 appeared unrelated to any clinicopathological factors and expression of $\mathrm{ObR}$ was unrelated to any factors other than tumour grade.

Survival rates. In the Kaplan-Meier analyses, progression-free and overall survival times were longer in cases with positive AdipoR-1 expression compared with negative AdipoR-1 expression, while survival time did not show any correlation with AdipoR-2 or ObR expression (Figs. 2 and 3; Tables III and IV).

Univariate and multivariate analyses. Univariate logistic regression analysis revealed that advanced-stage disease, high tumour grade, deeper myometrial invasion, cervical stromal invasion, adnexal invasion, involvement of the lymphovascular space, lymph node metastasis and negative AdipoR-1 expression were all significantly associated with poor progression-free survival. Similarly, multivariate Cox proportional hazard regression analysis revealed adnexal invasion and lymph node metastasis as independent variables associated with shorter progression-free survival (Table III). Univariate logistic regression analysis revealed that advanced-stage disease, high tumour grade, deeper myometrial invasion, cervical stromal invasion, adnexal 
A

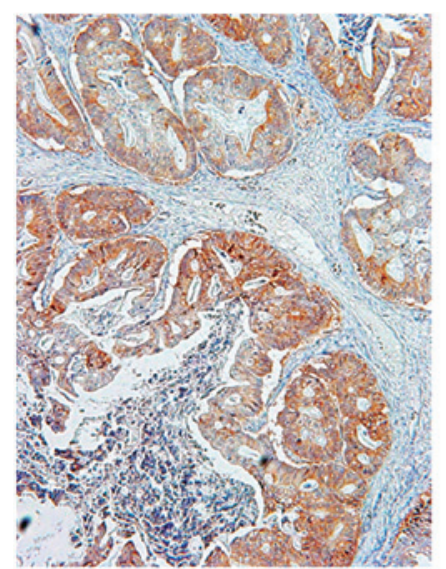

B

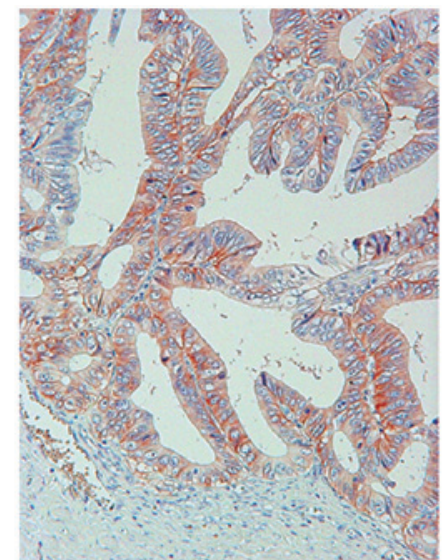

C

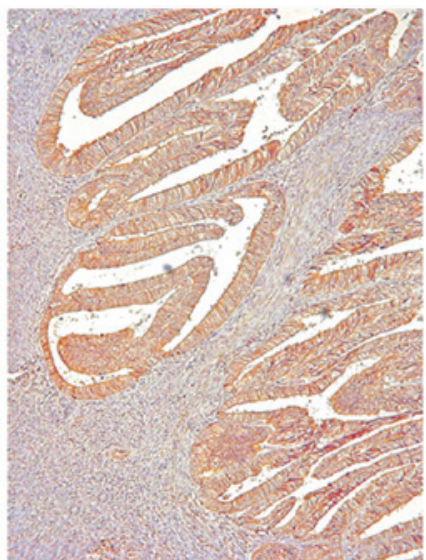

Figure 1. Representative examples of immunohistochemical visualisation of AdipoR-1, AdipoR-2 and ObR in endometrial carcinoma. (A) AdipoR-1 expression in G2 endometrioid adenocarcinoma and (B) AdipoR-2 and (C) ObR expression in G1 endometrioid adenocarcinoma. AdipoR-1, adiponectin receptor type 1; AdipoR-2, adiponectin receptor type 2; ObR, leptin receptor. Magnification, x200.

PFS

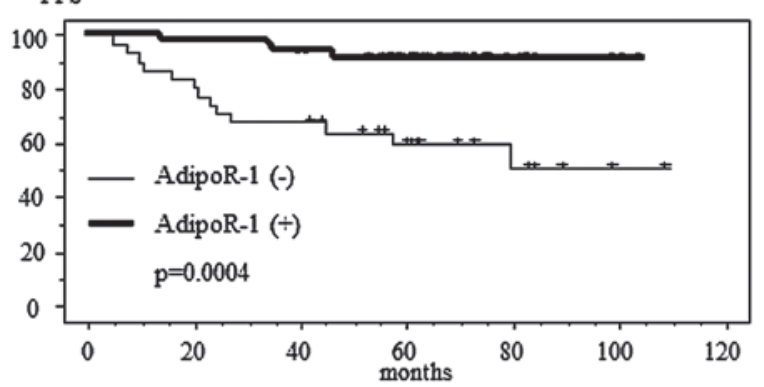

PFS

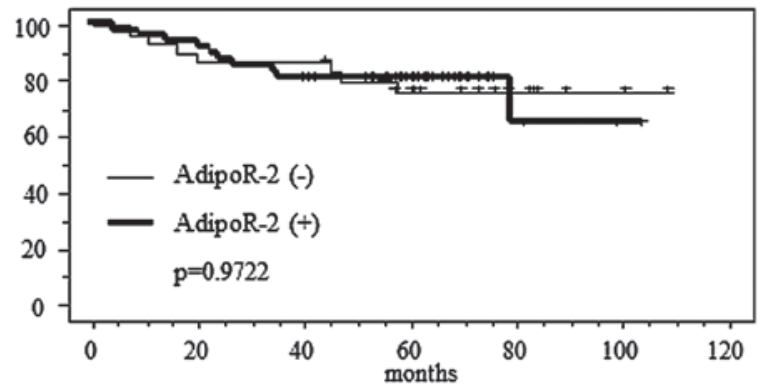

PFS

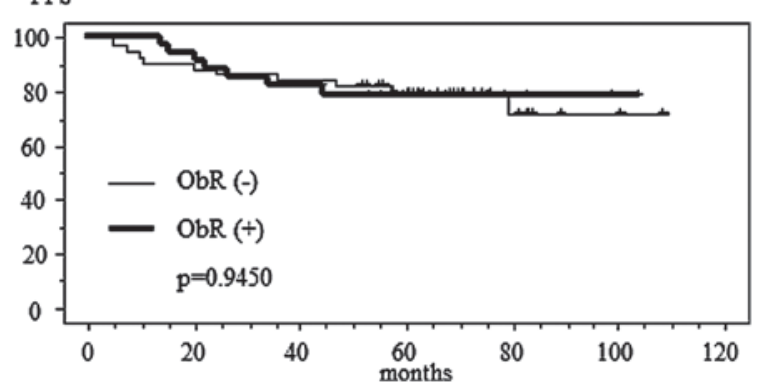

Figure 2. PFS was analysed using the Kaplan-Meier method and compared in relation to AdipoR-1, AdipoR-2 and ObR expression. PFS, progression-free survival; AdipoR-1, adiponectin receptor type 1; AdipoR-2, adiponectin receptor type 2; ObR, leptin receptor.

invasion, lymph node metastasis and negative AdipoR-1 expression were significantly associated with poor overall survival, while multivariate Cox proportional hazard
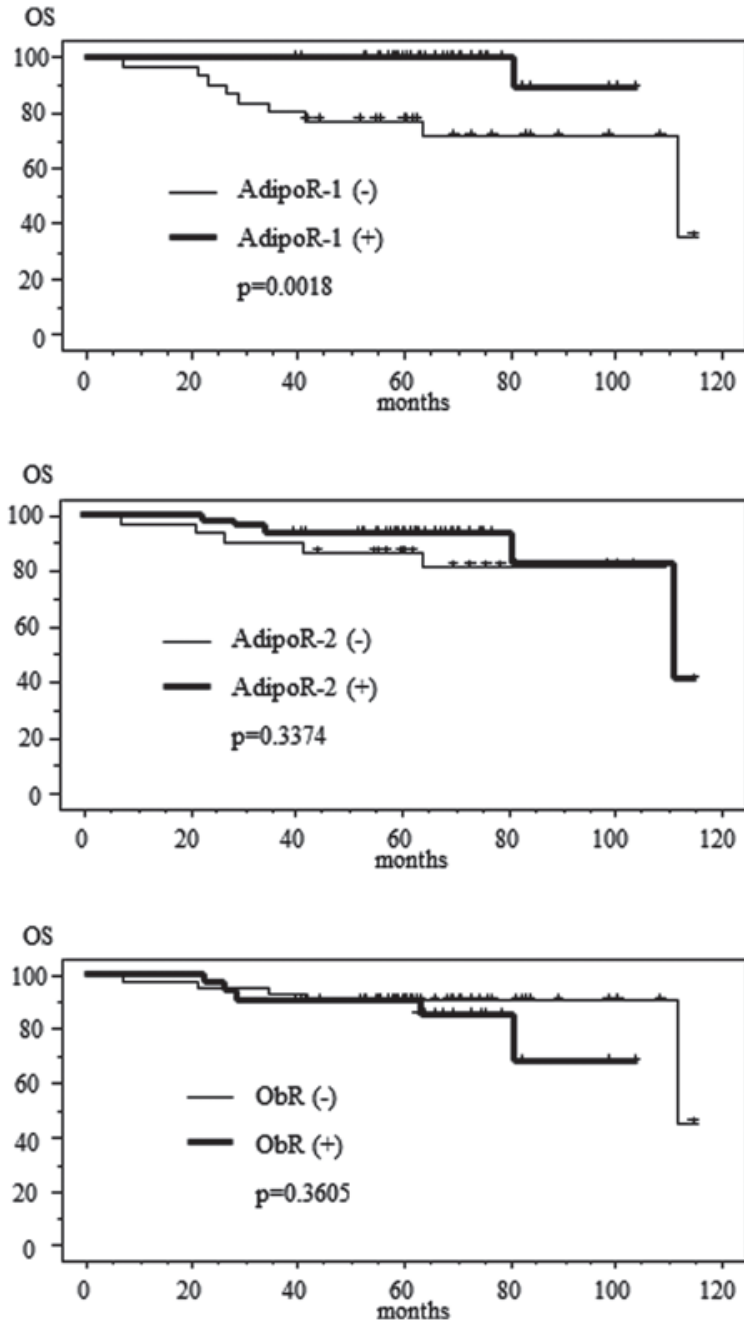

Figure 3. OS was analysed using the Kaplan-Meier method and compared in relation to AdipoR-1, AdipoR-2 and ObR expression. OS, overall survival; AdipoR-1, adiponectin receptor type 1; AdipoR-2, adiponectin receptor type 2; ObR, leptin receptor.

regression analysis revealed that adnexal invasion and lymph node metastasis were also identified as independent variables associated with shorter overall survival (Table IV). 


\section{Discussion}

Obesity is a known risk factor for endometrial cancer (8). Adipose tissues produce various bioactive substances called adipokines, the most prominent of which are leptin and adiponectin. Leptin has been found to positively correlate with obesity and is a well-known regulator of food intake and energy balance. By reducing tissue sensitivity to insulin, leptin is responsible for hyperinsulinaemia (35). Adiponectin has been found to negatively correlate with obesity, and low levels of adiponectin have been shown to have a high correlation with hyperinsulinaemia and the degree of insulin resistance independent of adiposity (36). These adipokines are reportedly associated with carcinogenesis and tumour growth in several types of cancer, including breast, colon, stomach and endometrial cancer (5-8). Serum concentrations of leptin are reportedly higher, and those of adiponectin lower, in patients with endometrial cancer compared with the control subjects $(26,37-40)$. The balance of leptin and adiponectin levels in individuals, rather than leptin or adiponectin levels alone, may indicate such physiological changes as the development of endometrial cancer (41).

Previously, adiponectin has been shown to exert suppressive effects on tumour development (42). Low adiponectin serum concentrations have been identified in patients affected by cancer $(38,42-44)$, including endometrial cancer. Serum adiponectin levels have been found to be inversely and independently associated with endometrial cancer (39).

The actions of adiponectin are mediated by binding to two receptors, AdipoR-1 and AdipoR-2 (31), and leptin actions are also mediated by binding to ObR.

Adiponectin has been previously reported to suppress endometrial cancer proliferation through AdipoRs and also increase the expression of the adaptor molecule, $L K B 1$, which is required for adiponectin-mediated activation of the AMPK/S6 axis and modulation of cell proliferation, colony formation, adhesion and invasion of endometrial carcinoma cell lines in vitro $(34,45)$. In addition, adiponectin reportedly acts to potently inhibit endothelial cell proliferation and migration in vitro and, in chick chorioallantoic membrane and mouse corneal angiogenesis assays, adiponectin shows marked activity in preventing new blood vessel growth. Furthermore, the antiendothelial mechanisms have been demonstrated to involve the activation of caspase-mediated endothelial cell apoptosis. Adiponectin induces the cascade activation of caspase- $8,-9$ and -3 , leading to cell death. In a previous mouse tumour model, adiponectin significantly inhibited primary tumour growth (23). Impaired tumour growth appeared to be associated with decreased neovascularisation, leading to significantly increased tumour cell apoptosis. These results demonstrated the induction of endothelial apoptosis as an unique mechanism for adiponectin-induced antiangiogenesis. Adiponectin, as a direct endogenous angiogenesis inhibitor, may have therapeutic implications in the treatment of angiogenesis-dependent diseases, including endometrial cancer (23).

The expression of these receptors has previously been documented in normal endometrium (46) and endometrial cancer tissues (47), but the role of AdipoR-1, AdipoR-2 and $\mathrm{ObR}$ in endometrial carcinoma has not been fully determined.
Table I. Characteristics of 77 patients with endometrioid adenocarcinoma of the endometrium.

Characteristics

$\begin{array}{lr}\text { Stage } & \\ \text { IA } & 30 \\ \text { IB } & 23 \\ \text { II } & 9 \\ \text { IIIA } & 2 \\ \text { IIIC } & 13 \\ \text { Grade } & \\ \text { G1 } & 39 \\ \text { G2 } & 22 \\ \text { G3 } & 16\end{array}$

Myometrial invasion

$<1 / 2 \quad 38$

$\geq 1 / 2 \quad 39$

Cervical stromal invasion

Negative $\quad 59$

Positive 18

Adnexal invasion

Negative $\quad 69$

Positive 8

Lymphovascular space involvement

Negative $\quad 52$

Positive 25

Lymph node metastasis

Negative $\quad 65$

Positive 12

Peritoneal cytology

$\begin{array}{ll}\text { Negative } & 61\end{array}$

Positive 16

Body mass index, $\mathrm{kg} / \mathrm{m}^{2}$

$<25 \quad 45$

$\geq 25$ to $<30 \quad 16$

$\geq 30$ to $<35 \quad 9$

$\geq 35 \quad 7$

Adjuvant therapy

None $\quad 26$

Radiotherapy 12

Chemotherapy $\quad 39$

AP 9

TJ 30

Age, years (mean \pm SD) $\quad 56.91 \pm 9.98$

AP, doxorubicin + cisplatin; TJ, paclitaxel + carboplatin.

The present study demonstrated that AdipoR-1, AdipoR-2 and ObR are expressed in endometrial carcinoma tissue, and that AdipoR-1 expression inversely correlates with high histological grade, deep myometrial invasion, involvement of the lymphovascular space, adnexal invasion and lymph node metastasis, and is associated with improved progression-free and overall survival. However, AdipoR-2 
Table II. Clinicopathological characteristics in relation to the immunohistochemical expression of AdipoR-1, AdipoR-2 and ObR in tumours obtained from 77 patients with endometrial carcinoma.

\begin{tabular}{|c|c|c|c|c|}
\hline Clinicopathological characteristics & $\mathrm{n}$ & AdipoR-1, n (\%) & AdipoR-2, n (\%) & ObR, n $(\%)$ \\
\hline \multicolumn{5}{|l|}{ Stage } \\
\hline IA & 30 & $23(76.7)$ & $18(60.0)$ & $10(33.3)$ \\
\hline IB & 23 & $14(60.9)$ & $14(60.9)$ & $13(56.5)$ \\
\hline II & 9 & $6(66.7)$ & $6(66.7)$ & $4(44.4)$ \\
\hline IIIA & 2 & $0(0.0)$ & $2(100)$ & $0(0.0)$ \\
\hline \multirow[t]{2}{*}{ IIIC } & 13 & $3(23.1)$ & $7(53.8)$ & $6(46.2)$ \\
\hline & & $\mathrm{P}=0.0073$ & $\mathrm{P}=0.7920$ & $\mathrm{P}=0.3507$ \\
\hline \multicolumn{5}{|l|}{ Grade } \\
\hline G1 & 39 & $34(87.2)$ & $27(69.2)$ & $18(46.2)$ \\
\hline $\mathrm{G} 2$ & 22 & $10(45.5)$ & $14(63.6)$ & $13(59.1)$ \\
\hline \multirow[t]{2}{*}{ G3 } & 16 & $2(12.5)$ & $6(37.5)$ & $2(12.5)$ \\
\hline & & $\mathrm{P}<0.0001$ & $\mathrm{P}=0.0867$ & $\mathrm{P}=0.0138$ \\
\hline \multicolumn{5}{|l|}{ Myometrial invasion } \\
\hline$<1 / 2$ & 38 & $29(76.3)$ & $24(63.2)$ & $14(36.8)$ \\
\hline \multirow[t]{2}{*}{$\geq 1 / 2$} & 39 & $17(43.6)$ & $23(59.0)$ & $19(48.7)$ \\
\hline & & $\mathrm{P}=0.0051$ & $\mathrm{P}=0.8162$ & $\mathrm{P}=0.3594$ \\
\hline \multicolumn{5}{|l|}{ Cervical stromal invasion } \\
\hline Negative & 59 & $38(64.4)$ & $35(59.3)$ & $25(42.4)$ \\
\hline \multirow[t]{2}{*}{ Positive } & 18 & $8(44.4)$ & $12(66.7)$ & $8(44.4)$ \\
\hline & & $\mathrm{P}=0.1720$ & $\mathrm{P}=0.7831$ & $\mathrm{P}=0.8765$ \\
\hline \multicolumn{5}{|l|}{ Adnexal invasion } \\
\hline Negative & 69 & $46(66.7)$ & $42(60.9)$ & $31(44.9)$ \\
\hline \multirow[t]{2}{*}{ Positive } & 8 & $0(0.0)$ & $5(62.5)$ & $2(25.0)$ \\
\hline & & $\mathrm{P}=0.0004$ & $\mathrm{P}=0.9287$ & $\mathrm{P}=0.4544$ \\
\hline \multicolumn{5}{|l|}{ Lymphovascular space involvement } \\
\hline Negative & 52 & $39(75.0)$ & $35(67.3)$ & $25(48.1)$ \\
\hline \multirow[t]{2}{*}{ Positive } & 25 & $7(28.0)$ & $12(48.0)$ & $8(32.0)$ \\
\hline & & $\mathrm{P}=0.0001$ & $\mathrm{P}=0.1360$ & $\mathrm{P}=0.2235$ \\
\hline \multicolumn{5}{|l|}{ Lymph node metastasis } \\
\hline Negative & 65 & $44(67.7)$ & $41(63.1)$ & $27(41.5)$ \\
\hline \multirow[t]{2}{*}{ Positive } & 12 & $2(29.2)$ & $6(50.0)$ & $6(50.0)$ \\
\hline & & $\mathrm{P}=0.0024$ & $\mathrm{P}=0.5216$ & $\mathrm{P}=0.7526$ \\
\hline \multicolumn{5}{|l|}{ Peritoneal cytology } \\
\hline Negative & 61 & $37(60.7)$ & $36(59.0)$ & $27(44.3)$ \\
\hline \multirow[t]{2}{*}{ Positive } & 16 & $9(56.3)$ & $11(68.8)$ & $6(37.5)$ \\
\hline & & $\mathrm{P}=0.7805$ & $\mathrm{P}=0.5722$ & $\mathrm{P}=0.7785$ \\
\hline \multicolumn{5}{|l|}{$\mathrm{BMI}, \mathrm{kg} / \mathrm{m}^{2}$} \\
\hline$<25$ & 45 & $27(60)$ & $29(64.4)$ & $20(44.4)$ \\
\hline \multirow[t]{2}{*}{$\geq 25$} & 32 & $19(59.4)$ & $18(56.3)$ & $13(40.6)$ \\
\hline & & $\mathrm{P}=0.9560$ & $\mathrm{P}=0.4872$ & $\mathrm{P}=0.8172$ \\
\hline Total & 77 & $46(59.7)$ & $47(61.0)$ & $33(42.9)$ \\
\hline
\end{tabular}

AdipoR-1, adiponectin receptor type 1; AdipoR-2, adiponectin receptor type 2; ObR, leptin receptor; BMI, body mass index.

and ObR expression was not found to correlate with any clinicopathological factors or survival in patients with endometrial carcinoma. Immunohistochemical expression of adiponectin in paired samples of endometrial carcinoma was also examined, but failed to observe any adiponectin expression in tumour cells or stromal elements (data not shown). Thus, the present results suggested that autocrine and paracrine stimulations of AdipoRs are unsuitable for endometrial carcinoma.

Previously, Yamauchi et al (47) reported that decreased AdipoR-1 expression significantly correlates with higher histological grade, myometrial invasion and lymph node metastasis of endometrioid adenocarcinoma. These results raised the possibility that the decreased expression of 
Table III. Uni- and multivariate analyses of variables associated with progression-free survival using the Kaplan-Meier method with log-rank test, logistic regression model and Cox proportional hazard model.

\begin{tabular}{|c|c|c|c|c|c|c|c|c|c|}
\hline \multirow[b]{2}{*}{ Variables } & \multirow[b]{2}{*}{$\mathrm{n}$} & \multicolumn{2}{|c|}{ Kaplan-Meier method } & \multicolumn{3}{|c|}{ Univariate analysis } & \multicolumn{3}{|c|}{ Multivariate analysis } \\
\hline & & survival rate, $\%$ & P-value & HR & $95 \% \mathrm{CI}$ & $\mathrm{P}$-value & HR & $95 \% \mathrm{CI}$ & P-value \\
\hline \multicolumn{10}{|l|}{ Stage } \\
\hline I & 53 & 92.10 & $<0.0001$ & -1.012 & $0.218-0.608$ & 0.0001 & -0.554 & $0.130-2.540$ & 0.4648 \\
\hline II/III & 24 & 49.20 & & & & & & & \\
\hline \multicolumn{10}{|l|}{ Grade } \\
\hline $\mathrm{G} 1 / \mathrm{G} 2$ & 61 & 88.50 & $<0.0001$ & -1.934 & $0.055-0.381$ & $<0.0001$ & -0.124 & $0.397-1.967$ & 0.7615 \\
\hline G3 & 16 & 43.80 & & & & & & & \\
\hline \multicolumn{10}{|c|}{ Myometrial invasion } \\
\hline$<1 / 2$ & 38 & 92.10 & 0.004 & -1.642 & $0.056-0.675$ & 0.0099 & 0.302 & $0.675-2.708$ & 0.394 \\
\hline$\leq 1 / 2$ & 39 & 66.20 & & & & & & & \\
\hline \multicolumn{10}{|c|}{ Cervical stromal invasion } \\
\hline Negative & 59 & 87.80 & 0.00001 & -1.724 & $0.066-0.483$ & 0.0007 & -0.457 & $0.222-1.808$ & 0.3932 \\
\hline Positive & 18 & 48.60 & & & & & & & \\
\hline \multicolumn{10}{|c|}{ Adnexal invasion } \\
\hline Negative & 69 & 86.50 & $<0.0001$ & -2.957 & $0.017-0.154$ & $<0.0001$ & -2.086 & $0.030-0.508$ & 0.0037 \\
\hline Positive & 8 & 12.50 & & & & & & & \\
\hline \multicolumn{10}{|c|}{$\begin{array}{l}\text { Lymphovascular space } \\
\text { involvement }\end{array}$} \\
\hline Negative & 52 & 85.90 & 0.0216 & -1.067 & $0.133-0.893$ & 0.0283 & -0.005 & $0.495-1.998$ & 0.9881 \\
\hline Positive & 25 & 63.80 & & & & & & & \\
\hline \multicolumn{10}{|c|}{ Lymph node metastasis } \\
\hline Negative & 65 & 90.40 & $<0.0001$ & -2.921 & $0.018-0.157$ & $<0.0001$ & -1.953 & $0.040-0.509$ & 0.0027 \\
\hline Positive & 12 & 12.50 & & & & & & & \\
\hline \multicolumn{10}{|c|}{ Peritoneal cytology } \\
\hline Negative & 61 & 81.60 & 0.237 & -0.623 & $0.188-1.531$ & 0.2445 & 0.635 & $0.605-5.886$ & 0.2741 \\
\hline Positive & 16 & 67.50 & & & & & & & \\
\hline \multicolumn{10}{|c|}{ AdipoR-1 expression } \\
\hline Negative & 31 & 59.90 & 0.0004 & 1.780 & $1.928-18.246$ & 0.0019 & -0.068 & $0.454-1.921$ & 0.8525 \\
\hline Positive & 46 & 91.20 & & & & & & & \\
\hline \multicolumn{10}{|c|}{ AdipoR-2 expression } \\
\hline Negative & 30 & 75.90 & 0.9722 & 0.017 & $0.384-2.697$ & 0.9722 & -0.363 & $0.361-1.340$ & 0.2779 \\
\hline Positive & 47 & 80.90 & & & & & & & \\
\hline \multicolumn{10}{|c|}{ ObR expression } \\
\hline Negative & 44 & 79.20 & 0.945 & 0.034 & $0.393-2.723$ & 0.945 & -0.218 & $0.409-1.580$ & 0.5273 \\
\hline Positive & 33 & 78.30 & & & & & & & \\
\hline \multicolumn{10}{|c|}{$\mathrm{BMI}, \mathrm{kg} / \mathrm{m}^{2}$} \\
\hline$<25$ & 45 & 82.20 & 0.3527 & 0.126 & $0.716-1.797$ & 0.5907 & -0.069 & $0.570-1.529$ & 0.7834 \\
\hline$\geq 25$ & 32 & 74.00 & & & & & & & \\
\hline \multicolumn{10}{|l|}{ Age, years } \\
\hline$<60$ & 45 & 79.50 & 0.9015 & -0.042 & $0.606-1.516$ & 0.8567 & 0.083 & $0.549-2.151$ & 0.8121 \\
\hline
\end{tabular}

HR, hazard ratio; CI, confidence interval; AdipoR-1, adiponectin receptor type 1; AdipoR-2, adiponectin receptor type 2; ObR, leptin receptor; BMI, body mass index.

AdipoRs is implicated in the development, invasion and metastasis of human endometrioid adenocarcinoma. Thus, AdipoRs may be considered as therapeutic targets for endometrioid adenocarcinoma. In AdipoR-positive endometrioid adenocarcinoma, adiponectin-based anticancer therapy may prove useful. In addition, Yamauchi et al (47) commented that AdipoR-1 and AdipoR-2 may be considered as therapeutic targets for endometrioid adenocarcinomas. Methods leading to the upregulation of AdipoRs or development of specific AdipoR agonists (such as osmotin) may prove 
Table IV. Uni- and multivariate analyses of variables associated with overall survival using the Kaplan-Meier method with log-rank test, logistic regression model and Cox proportional hazard model.

\begin{tabular}{|c|c|c|c|c|c|c|c|c|c|}
\hline \multirow[b]{2}{*}{ Variables } & \multirow[b]{2}{*}{$\mathrm{n}$} & \multicolumn{2}{|c|}{ Kaplan-Meier method } & \multicolumn{3}{|c|}{ Univariate analysis } & \multicolumn{3}{|c|}{ Multivariate analysis } \\
\hline & & $\begin{array}{c}\text { Five-year } \\
\text { survival rate, } \%\end{array}$ & P-value & HR & $95 \% \mathrm{CI}$ & P-value & $\mathrm{HR}$ & $95 \% \mathrm{CI}$ & P-value \\
\hline \multicolumn{10}{|l|}{ Stage } \\
\hline I & 53 & 100 & $<0.0001$ & -0.894 & $0.244-0.687$ & 0.0007 & -0.871 & $0.097-1.808$ & 0.2431 \\
\hline $\mathrm{II} / \mathrm{III}$ & 24 & 70.80 & & & & & & & \\
\hline \multicolumn{10}{|l|}{ Grade } \\
\hline $\mathrm{G} 1 / \mathrm{G} 2$ & 61 & 95.1 & 0.0101 & -1.575 & $0.055-0.777$ & 0.0196 & 0.655 & $0.838-4.422$ & 0.1228 \\
\hline G3 & 16 & 75.0 & & & & & & & \\
\hline \multicolumn{10}{|c|}{ Myometrial invasion } \\
\hline$<1 / 2$ & 38 & 100 & 0.0177 & -2.106 & $0.015-0.974$ & 0.0472 & 0.208 & $0.616-2.461$ & 0.5566 \\
\hline$\geq 1 / 2$ & 39 & 82.10 & & & & & & & \\
\hline \multicolumn{10}{|c|}{ Cervical stromal invasion } \\
\hline Negative & 59 & 94.90 & 0.0078 & -1.653 & $0.049-0.741$ & 0.0166 & 0.837 & $0.748-7.123$ & 0.1454 \\
\hline Positive & 18 & 77.80 & & & & & & & \\
\hline \multicolumn{10}{|c|}{ Adnexal invasion } \\
\hline Negative & 69 & 98.60 & $<0.0001$ & -3.867 & $0.004-0.108$ & $<0.0001$ & -2.266 & $0.032-0.340$ & 0.0002 \\
\hline Positive & 8 & 25.0 & & & & & & & \\
\hline \multicolumn{10}{|c|}{$\begin{array}{l}\text { Lymphovascular space } \\
\text { involvement }\end{array}$} \\
\hline Negative & 52 & 96.20 & 0.0607 & -1.156 & $0.088-1.125$ & 0.0752 & 0.192 & $0.577-2.545$ & 0.6125 \\
\hline Positive & 25 & 80.0 & & & & & & & \\
\hline \multicolumn{10}{|c|}{ Lymph node metastasis } \\
\hline Negative & 65 & 100 & $<0.0001$ & -4.510 & $0.001-0.093$ & $<0.0001$ & -1.193 & $0.107-0.860$ & 0.0248 \\
\hline Positive & 12 & 41.70 & & & & & & & \\
\hline \multicolumn{10}{|c|}{ Peritoneal cytology } \\
\hline Negative & 61 & 93.40 & 0.0368 & -1.313 & $0.072-1.009$ & 0.0515 & -0.109 & $0.332-2.425$ & 0.8306 \\
\hline Positive & 16 & 81.30 & & & & & & & \\
\hline \multicolumn{10}{|c|}{ AdipoR-1 expression } \\
\hline Negative & 31 & 77.40 & 0.0018 & 2.565 & $1.620-10.427$ & 0.0158 & 0.026 & $0.478-2.202$ & 0.947 \\
\hline Positive & 46 & 100 & & & & & & & \\
\hline \multicolumn{10}{|c|}{ AdipoR-2 expression } \\
\hline Negative & 30 & 86.70 & 0.3374 & 0.637 & $0.504-7.092$ & 0.3453 & 0.387 & $0.796-2.726$ & 0.2176 \\
\hline Positive & 47 & 93.60 & & & & & & & \\
\hline \multicolumn{10}{|c|}{ ObR expression } \\
\hline Negative & 44 & 90.90 & 0.3605 & -0.608 & $0.145-2.043$ & 0.3676 & -0.432 & $0.321-1.312$ & 0.2284 \\
\hline Positive & 33 & 90.90 & & & & & & & \\
\hline \multicolumn{10}{|c|}{ BMI, $\mathrm{kg} / \mathrm{m}^{2}$} \\
\hline$<25$ & 45 & 91.10 & 0.2739 & 0.095 & $0.696-1.737$ & 0.685 & 0.034 & $0.610-1.754$ & 0.8988 \\
\hline$\geq 25$ & 32 & 90.60 & & & & & & & \\
\hline \multicolumn{10}{|l|}{ Age, years } \\
\hline$<60$ & 45 & 91.10 & 0.9348 & -0.024 & $0.617-1.546$ & 0.9186 & -0.192 & $0.417-1.636$ & 0.5828 \\
\hline$\geq 60$ & 32 & 90.60 & & & & & & & \\
\hline
\end{tabular}

$\mathrm{HR}$, hazard ratio; CI, confidence interval; AdipoR-1, adiponectin receptor type 1; AdipoR-2, adiponectin receptor type 2; ObR, leptin receptor; BMI, body mass index.

beneficial in the treatment of endometrioid adenocarcinomas, and the results of the current study appear to support this perspective.
Several limitations must be considered when interpreting the results of the present study. Firstly, the immunohistochemical expression of AdipoR-1, AdipoR-2 and ObR were 
analysed, but gene and protein expression levels were not revealed in endometrial carcinoma. Secondly, the present study was unable to assume that correlations exist between serum adiponectin or leptin levels and the expression of AdipoRs and ObR in patients with endometrial carcinoma. Despite these limitations, we considered the present observations to be meaningful, since they provide evidence that AdipoR-1 levels are inversely correlated with the biologically malignant phenotypes of endometrial carcinoma, and that endometrial cancer patients with positive expression of AdipoR-1 experience an improved prognosis in terms of progression-free and overall survival.

In conclusion, the present study demonstrated the expression of AdipoR-1, AdipoR-2 and ObR in human endometrioid adenocarcinoma of the uterine corpus. In addition, the decreased expression of AdipoR-1 molecules was associated with tumour growth, invasion and metastasis, representing factors predictive of poor prognosis in patients with endometrial carcinoma. Furthermore, adiponectin-based anticancer therapies may prove useful for treating endometrial cancer.

\section{References}

1. Matsuda T, Marugame T, Kamo K, Katanoda K, Ajiki W and Sobue T; Japan Cancer Surveillance Research Group: Cancer incidence and incidence rates in Japan in 2006: based on data from 15 population-based cancer registries in the monitoring of cancer incidence in Japan (MCIJ) project. Jpn J Clin Oncol 42: $139-147,2012$.

2. Morrow CP, Bundy BN, Kurman RJ, Creasmann WT, Heller P, Homesley HD and Graham JE: Relationship between surgical-pathological risk factors and outcome in clinical stage I and II carcinoma of the endometrium: A Gynecologic Oncology Group Study. Gynecol Oncol 40: 55-65, 1991.

3. Creasman WT, Morrow CP, Bundy BN, Homesley HD, Graham JE and Heller PB: Surgical pathologic spread patterns of endometrial cancer. A Gynecologic Oncology Group Study. Cancer 60 (Suppl 8): S2035-S2041, 1987.

4. DiSaia PJ, Creasmann WT, Boronow RC and Blessing JA: Risk factors and recurrent patterns in Stage I endometrial cancer. Am J Obstet Gynecol 151: 1009-1015, 1985.

5. Ishikawa M, Kitayama J, Kazama S, Hiramatsu T, Hatano K and Nagawa H: Plasma adiponectin and gastric cancer. Clin Cancer Res 11: 466-472, 2005.

6. Wei EK, Giovannucci E, Fuchs CS, Willett WC and Mantzoros CS: Low plasma adiponectin levels and risk of colorectal cancer in men: a prospective study. J Natl Cancer Inst 97: 1688-1694, 2005.

7. Mantzoros C, Petridou E, Dessypris N, Chavelas C, Dalagama M, Alexe DM, Papadiamantis Y, Markopoulos C, Spanos E, Chrousos G and Trichopoulos D: Adiponectin and breast cancer risk. J Clin Endocrinol Metab 89: 1102-1107, 2004.

8. Dal Maso L, Augustin LS, Karalis A, Talamini R, Franceschi S, Trichopoulos D, Mantzoros CS and La Vecchia C: Circulating adiponectin and endometrial cancer risk. J Clin Endocrinol Metab 89: 1160-1163,2004.

9. Judd HL, Shamonki IM, Frumar AM and Lagasse LD: Origin of serum estradiol in postmenopausal women. Obstet Gynecol 59: 680-686, 1982

10. Berstein LM, Kvatchevskaya JO, Poroshina TE, Kovalenko IG, Tsyrlina EV, Zimarina TS, Ourmantcheeva AF, Ashrafian L and Thijssen JH: Insulin resistance, its consequences for the clinical course of the disease, and possibilities of correction in endometrial cancer. J Cancer Res Clin Oncol 130: 687-693, 2004.

11. Vona-Davis L and Rose DP: Angiogenesis, adipokines and breast cancer. Cytokine Growth Factor Rev 20: 193-201, 2009.

12. Housa D, Housová J, Vernerová Z and Haluzík M: Adipocytokines and cancer. Physiol Res 55: 233-244, 2006.

13. Garofalo C and Surmacz E: Leptin and cancer. J Cell Physiol 207: 12-22, 2006.

14. Zhang Y, Proenca R, Maffei M, Barone M, Leopold L and Friedman JM: Positional cloning of the mouse obese gene and its human homologue. Nature 372: 425-432, 1994.
15. Hu X, Juneja SC, Maihle NJ and Cleary MP: Leptin - a growth factor in normal and malignant breast cells and for normal mammary gland development. J Natl Cancer Inst 94: 1704-1711, 2002.

16. Jardé T, Caldefie-Chézet F, Damez M, Mishellany F, Perrone D, Penault-Llorca F, Guillot J and Vasson MP: Adiponectin and leptin expression in primary ductal breast cancer and in adjacent healthy epithelial and myoepithelial tissue. Histopathology 53: 484-487, 2008.

17. Ishikawa M, Kitayama J and Nagawa H: Enhanced expression of leptin and leptin receptor (OB-R) in human breast cancer. Clin Cancer Res 10: 4325-4331, 2004.

18. Tessitore L, Vizio B, Jenkins O, De Stefano I, Ritossa C, Argiles JM, Benedetto C and Mussa A: Leptin expression in colorectal and breast cancer patients. Int J Mol Med. 5: 421-426, 2000.

19. Huang L and Li C: Leptin: a multifunctional hormone. Cell Res 10: 81-92, 2000.

20. Saxena NK, Taliaferro-Smith L, Knight BB, Merlin D, Anania FA, O'Regan RM and Sharma D: Bidirectional crosstalk between leptin and insulin-like growth factor-I signaling promotes invasion and migration of breast cancer cells via transactivation of epidermal growth factor receptor. Cancer Res 68: 9712-9722, 2008.

21. Garofalo C, Koda M, Cascio S, Sulkowska M, Kanczuga-Koda L, Golaszewska J, Russo A, Sulkowski S and Suemacz E: Increased expression of leptin and the leptin receptor as a marker of breast cancer progression: possible role of obesity-related stimuli. Clin Cancer Res 12: 1447-1453, 2006.

22. Arita Y, Kihara S, Ouchi N, Takahashi M, Maeda K, Miyagawa J, Hotta K, Shimomura I, Nakamura T, Miyaoka K, et al: Paradoxical decrease of an adipose-specific protein, adiponectin, in obesity. 1999. Biochem Biophys Res Commun 425: 560-564, 2012.

23. Bråkenhielm E, Veitonmäki N, Cao R, Kihara S, Matsuzawa Y, Zhivotovsky B, Funahashi T and Cao Y: Adiponectin-induced antiangiogenesis and antitumor activity involve caspase-mediated endothelial cell apoptosis. Proc Natl Acad Sci USA 101: 2476-2481, 2004.

24. Ogunwobi OO and Beales IL: Globular adiponectin, acting via adiponectin receptor-1, inhibits leptin-stimulated oesophageal adenocarcinoma cell proliferation. Mol Cell Endocrinol 285: 43-50,2008.

25. Ishikawa M, Kitayama J, Yamauchi T, Kadowaki T, Maki T, Miyato $\mathrm{H}$, Yamashita $\mathrm{H}$ and Nagawa $\mathrm{H}$ : Adiponectin Inhibits the growth and peritoneal metastasis of gastric cancer through its specific membrane receptors AdipoR1 and AdipoR2. Cancer Sci 98: 1120-1127, 2007.

26. Rzepka-Górska I, Bedner R, Cymbaluk-Płoska A and Chudecka-Głaz A: Serum adiponectin in relation to endometrial cancer and endometrial hyperplasia with atypia in obese women. Eur J Gynaecol Oncol 29: 594-597, 2008.

27. Yamauchi T, Kamon J, Ito Y, Tsuchida A, Yokomizo T, Kita S, Sugiyama T, Miyagishi M, Hara K, Tsunoda M, et al: Cloning of adiponectin receptors that mediate antidiabetic metabolic effects. Nature 423: 762-769, 2003.

28. Luo XH, Guo LJ, Yuan LQ, Xie H, Zhou HD, Wu XP and Liao EY: Adiponectin stimulates human osteoblasts proliferation and differentiation via the MAPK signaling pathway. Exp Cell Res 309: 99-109, 2005.

29. Fasshauer M, Klein J, Kralisch S, Klier M, Lössner U, Blüher M and Paschke R: Growth hormone is a positive regulator of adiponectin receptor 2 in 3T3-L1 adipocytes. FEBS Lett 558: 27-32, 2004.

30. Kharroubi I, Rasschaert J, Eizirik DL and Cnop M: Expression of adiponectin receptors in pancreatic beta cells. Biochem Biophys Res Commun 312: 1118-1122, 2003.

31. Kadowaki T and Yamauchi T: Adiponectin and adiponectin receptors. Endocrine Rev 26: 439-451, 2005.

32. Kadowaki T, Yamauchi T, Kubota N, Hara K, Ueki K and Tobe K: Adiponectin and adiponectin receptors in insulin resistance, diabetes, and the metabolic syndrome. J Clin Invest 116: 1784-1792, 2006.

33. Takahata $\mathrm{C}$, Miyoshi Y, Irahara N, Taguchi T, Tamaki $\mathrm{Y}$ and Noguchi S: Demonstration of adiponectin receptors 1 and 2 mRNA expression in human breast cancer cells. Cancer Lett 250: 229-236, 2007.

34. Cong L, Gasser J, Zhao J, Yang B, Li F and Zhao AZ: Human adiponectin inhibits cell growth and induces apoptosis in human endometrial carcinoma cells, HEC-1-A and RL95-2. Endocrine Relat Cancer 14: 713-720, 2007. 
35. Gnacińska M, Małgorzewicz S, Stojek M, Łysiak-Szydłowska W and Sworczak K: Role of adipokines in complications related to obesity: a review. Adv Med Sci 54: 150-157, 2009.

36. Hanley AJ, Bowden D, Wagenknecht LE, Balasubramanyam A Langfeld C, Saad MF, Rotter JI, Guo X, Chen YD, Bryer-Ash M, et al: Associations of adiponectin with body fat distribution and insulin sensitivity in nondiabetic Hispanics and African-Americans. J Clin Endocrinol Metab 92: 2665-2671, 2007.

37. Petridou E, Mantzoros C, Dessypris N, Koukoulomatis P, Addy C, Voulgaris Z, Chrousos G and Trichopoulos D: Plasma adiponectin concentrations in relation to endometrial cancer: a case-control study in Greece. J Clin Endocrinol Metab 88: 993-997, 2003

38. Cymbaluk A, Chudecka-Głaz A and Rzepka-Górska I: Leptin levels in serum depending on Body Mass Index in patients with endometrial hyperplasia and cancer. Eur J Obstet Gynecol Reprod Biol 136: 74-77, 2008.

39. Soliman PT, Wu D, Tortolero-Luna G, Schmeler KM, Slomovitz BM, Bray MS, Gershenson DM and Lu KH: Association between adiponectin, insulin resistance, and endometrial cancer. Cancer 106: 2376-2381, 2006.

40. Cust AE, Kaaks R, Friedenreich C, Bonnet F, Laville M, Lukanova A, Rinaldi S, Dossus L, Slimani N, Lundin E, et al: Plasma adiponectin levels and endometrial cancer risk in pre- and postmenopausal women. J Clin Endocrinol Metab 92: 255-263, 2007.
41. Ashizawa N, Yahata T, Quan J, Adachi S, Yoshihara K and Tanaka K: Serum leptin-adiponectin ratio and endometrial cancer risk in postmenopausal female subjects. Gynecol Oncol 119: 65-69, 2010.

42. Kelesidis I, Kelesidis T and Mantzoros CS: Adiponectin and cancer: a systemic review. Br J Cancer 94: 1221-1225, 2006.

43. Petridou E, Mantzoros C, Dessypris N, Dikalioti SK and Trichopoulos D: Adiponectin in relation to childhood myeloblastic leukaemia. Br J Cancer 94: 156-160, 2006.

44. Goktas S, Yilmaz MI, Caglar K, Sonmez Z, Kilic S and Bedir S: Prostate cancer and adiponectin. Urology 65: 1168-1172, 2005.

45. Moon HS, Chamberland J, Aronis K, Tseleni-Balafonta S and Mantzoros C: Direct role of adiponectin and adiponectin receptors in endometrial cancer: in vitro and ex vivo studies in humans. Mol Cancer Ther 10: 2234-2243, 2011.

46. Takemura Y, Osuga J, Yamauchi T, Kobayashi M, Harada M, Hirata T, Morimoto C, Hirota Y, Yoshino O, Koga K, et al: Expression of adiponectin receptors and its possible implication in the human endometrium. Endocrinology 147: 3203-3210, 2006.

47. Yamauchi N, Takazawa Y, Maeda D, Hibiya T, Tanaka M, Iwabu M, Okada-Iwabu M, Yamauchi T, Kadowaki T and Fukayama M: Expression levels of adiponectin receptors are decreased in human endometrial adenocarcinoma tissues. Int J Gynecol Pathol 31: 352-357, 2012. 